\title{
Peripartum cardiomyopathy and thrombotic complications
}

\author{
(1) Ugur Aksu, ${ }^{1}$ (D) Selim Topcu, ${ }^{2}$ (D) Oktay Gulcu, ${ }^{1}$ ㄴ) Ibrahim Halil Tanboga ${ }^{2}$ \\ ${ }^{1}$ Department of Cardiology, Erzurum Training and Research Hospital, Erzurum, Turkey \\ ${ }^{2}$ Department of Pathology, Ataturk University Faculty of Medicine, Erzurum, Turkey
}

Cite this article as: Aksu U, Topcu S, Gulcu O, Tanboga IH. Peripartum cardiomyopathy and thrombotic complications. North Clin Istanb 2019;6(1):102.

We would like to thank Biteker et al. [1] for their interest and positive and constructive comments regarding our case [2]. Peripartum cardiomyopathy (PPCMP) is a life-threatening clinical condition in which thromboembolic complications are frequent. Both the prothrombotic status of pregnancy and stasis as a result of heart failure may lead to thromboembolic complications [3]. The incidence of PPCMP and cardiac thrombus in literature is very variable. In one study, the incidence was reported to be $17 \%$, while another study indicated $30 \%$ $[4,5]$. It has even been reported in previous studies that up to $53 \%$ of cases of PPCMP have thromboembolism $[6,7]$. In conclusion, the exact incidence of these patients is not known since they are both rare and could be diagnosed as a result of thromboembolic complications such as pulmonary embolism or ischemic stroke [8].

The decision of anticoagulant therapy in PPCMP patients is still controversial, and the patient's compliance, the degree of heart failure, and other clinical conditions should be taken into account when deciding on anticoagulant therapy [8].

\section{REFERENCES}

1. Biteker M, Çil C, Çelik O, Gökçek A, Kayataş K. The Therapeutic Dilemma of Peripartum Cardiomyopathy. North Clin Istanb 2019;6:100-1.

2. Aksu U, Topcu S, Gulcu O, Tanboga IH. Peripartum cardiomyopathy and ventricular thrombus: A case report and review of literature. North Clin Istanb 2018;5:145-7.

3. Hilfiker-Kleiner D, Haghikia A, Nonhoff J, Bauersachs J. Peripartum cardiomyopathy: Current management and future perspectives. Eur Heart J 2015;36:1090-7. [CrossRef]

4. Amos AM, Jaber WA, Russell SD. Improved outcomes in peripartum cardiomyopathy with contemporary. Am Heart J 2006;152:509-13.

5. Kane A, Mbaye M, Ndiaye MB, Diao M, Moreira PM, Mboup C, et al. Evolution and thromboembolic complications of the idiopathic peripartal cardiomyopathy at Dakar university hospital: Forwardlooking study about 33 cases. J Gynecol Obstet Biol Reprod (Paris) 2010;39:484-489. [CrossRef]

6. Demakis JG, Rahimtoola SH. Peripartum cardiomyopathy. Circulation1 971;44:964-968.

7. Demakis JG, Rahimtoola SH, Sutton GC, Meadows WR, Szanto PB, Tobin JR, et al. Natural course of peripartum cardiomyopathy. Circulation 1971;44:1053-61. [CrossRef]

8. Arany Z, Elkayam U. Peripartum cardiomyopathy. Circulation 2016;133:1397-409. [CrossRef] 